\title{
Análise da amplitude de hospedeiros de vírus bacterianos isolados de amostras de esgoto doméstico da cidade de Macapá
}

\author{
Analysis of the host range of bacteriophages isolated from samples of \\ domestic sewage from Macapá city
}

\author{
Anderson Luiz Pena Costa 1* $^{*}$, Orlando Alves Rodrigues Neto 2 , Antonio Carlos Freitas \\ Souza ${ }^{3}$, Rafael Lima Resque 4 \\ ${ }^{1}$ Biólogo, Mestre em Ciências Farmacêuticas pela Universidade Federal do Amapá. Brasil. E-mail: pena.biologo@gmail.com * Autor para \\ correspondência \\ ${ }^{2}$ Acadêmico de Farmácia do Instituto Macapaense de Ensino Superior-IMMES. Brasil. E-mail: orlandonetoof@gmail.com \\ ${ }^{3}$ Biólogo, Mestre em Ciências da Saúde, Pesquisador do Instituto de Pesquisas Científicas e Tecnológicas do Estado do Amapá-IEPA e docente \\ do colegiado de farmácia do Instituto Macapaense de Ensino Superior-IMMES Brasil.E-mail: jr_bio2005@yahoo.com.br \\ ${ }^{4}$ Farmacêutico, Doutor em Genética e Biologia Molecular, Docente do colegiado de farmácia da Universidade Federal do Amapá-UNIFAP \\ Brasil E-mail: rafaellresque@gmail.com
}

\author{
Palavras-chave \\ Bacteriófagos \\ Agentes anti-infecciosos \\ Antimicrobiano
}

\begin{abstract}
Bacteriófagos ou fagos, são vírus que infectam e matam bactérias com grande seletividade, por isso, possuem grande aplicabilidade terapêutica e biotecnológica para o controle de bactérias de forma abrangente ou especifica em função de sua amplitude de hospedeiros, ou seja, a capacidade de infectar e lisar diferentes espécies bacterianas. $\mathrm{O}$ que os potencializa como uma poderosa ferramenta para o biocontrole bacteriano, incluindo patógenos, principalmente em um contexto na qual a resistência bacteriana aos antibióticos ameaça a eficácia desses fármacos e gera muitos impactos negativos sobre a saúde pública ao nível global. Fato este que torna relevante a realização de pesquisas com o intuito de isolar e explorar o potencial biotecnológico/terapêutico destes vírus como alternativa aos antibióticos. Neste contexto, este trabalho teve como objetivo isolar e caracterizar a amplitude de hospedeiros de bacteriófagos líticos provenientes de amostras de um esgoto da cidade de Macapá por meio de ensaios clássicos de microbiologia, que tiveram como resultado o isolamento de 4 bacteriófagos líticos, das quais 3 apresentaram amplitude de hospedeiro polivalente e 1 amplitude de hospedeiro do tipo monovalente.
\end{abstract}

\section{Keywords}

Bacteriophages

Anti-infectives

Antimicrobial
Bacteriophages, or phages, are viruses that infect and kill bacteria with high selectivity, so they have great therapeutic and biotechnological applicability for the control of bacteria in a wide or specific way depending on their host range, ie the ability to infect and lyse different bacterial species. This potentializes them as a powerful tool for bacterial biocontrol, including pathogens, especially in a context in which the bacterial resistance to the antibiotics threatens the efficacy of these drugs and generates many negative impacts over the public health globally. This fact makes research relevant to isolate and exploit the biotechnological/therapeutic potential of these viruses as an alternative to antibiotics. In this context, this work aimed to isolate and characterize the host range of lytic bacteriophage isolated from samples of sewage from the city of Macapá by classical microbiology assays, which resulted in the isolation of 4 lytic bacteriophages, of which 3 presented polyvalent host amplitude and 1 monovalent host amplitude.

\section{INTRODUÇÃO}

Os antibióticos são fármacos efetivos contra infecções bacterianas que permitiram às populações humanas o alcance de uma considerável longevidade e qualidade de vida em decorrência de avanços na medicina, como procedimentos cirúrgicos invasivos, prevenção e tratamento de infecções bacterianas em pacientes sobre esquemas terapêuticos com quimioterápicos, ou portadores de doenças crônicas que os tornem suscetíveis as infecções, que só se tornaram possíveis em decorrência dos antibióticos, que contribuíram significativamente para a redução das taxas de morbidade e mortalidade mundiais (VENTOLA, 2015).

Entretanto, ao mau uso destes fármacos é atribuído o surgimento da resistência bacteriana, que tem se tornado um sério problema de saúde global devido a um número consideravelmente maior de complicações clínicas, prolongação do tempo de tratamento, hospitalização e relevante elevação dos custos (SIQUEIRA, 2004; COSTA; SILVAJÚNIOR, 2017), além de sua influência em eventos epidêmicos de emergência e re-emergência de doenças infecciosas. O que torna importante a busca de estratégias e alternativas contra 
a resistência bacteriana (COHEN, 2000; HEYMANN; DAR, 2014).

Neste contexto, bacteriófagos, vírus que infectam e matam bactérias, ou seja, predadores naturais de bactérias, possuem grande potencial terapêutico e biotecnológico para o controle bacteriano. Sendo estes vírus conhecidos desde 1919, mas devido a descoberta e lançamento dos antibióticos no mercado em associação a um marketing de que estes fármacos seriam a cura de todas as infecções, passaram por um longo período de esquecimento (FRUCIANO; BOURNE, 2007; GOLKAR et al., 2014), porém, o aumento na incidência e prevalência global de casos de infecções causadas por bactérias resistentes ou multi-resistentes aos antibióticos contribuiu para o renascimento de pesquisas com estes vírus com propósito terapêutico (PELFRENE et al., 2016).

Sendo apontado como principais vantagens a utilização de fagos ao invés dos antibióticos (moléculas estáticas) na terapêutica principalmente a capacidade biológica destes vírus de acompanhar a evolução biológica das bactérias, sua farmacologia atípica não envolver mecanismos farmacocinéticos e farmacodinâmicos implícitos as drogas químicas, e sua autoreplicação tornar o tratamento ativo e mais confortável, por dispensar esquemas posológicos inconvenientes para manutenção da janela terapêutica em função da replicação viral; também devendo ser considerado que a abundância e diversidade destas entidades biológicas nos mais diversos ecossistemas é colossal (ABEADON et al., 2010; ABEADON et al., 2011; LOC-CARRILLO; ABEDON, 2011) e seu potencial biotecnológico é pouco explorado, principalmente na Amazônia.

Em meio a este âmbito, este trabalho teve como objetivo isolar bacteriófagos líticos oriundos de amostras de um esgoto da cidade de Macapá e analisar a amplitude de hospedeiro dos isolados contra 6 cepas de bactérias patogênicas ao homem por meio ensaios in vitro.

\section{MATERIAL E MÉTODOS}

As amostras de esgoto utilizadas neste trabalho foram coletadas em um efluente de esgoto doméstico despejado no curso do igarapé das pedrinhas (georreferenciamento $0^{\circ}$ $0.112^{\prime} \mathrm{N} 51^{\circ} 4.219^{\prime}$ ) com auxílio de pipetas de pasteur e frascos de rosca estéreis, e o devido cuidado para evitar contaminação cruzada. Tendo o procedimento de coleta ocorrido no mês de julho de 2018.

Os procedimentos de prospecção e isolamento foram realizados pelo ensaio de placa com o método de dupla camada de ágar, seguido por coleta de placa e cultivos subsequente para assegurar o isolamento conforme descrito por Mirzaei e Nilsson (2015), tendo sido utilizados como hospedeiros para a obtenção e isolamento de fagos as cepas Staphylococcus aureus ATCC 6338, Klebisiela pneumoniae ATCC 4352 Escherichia coli ATCC 8789 e Pseudomonas aeruginosa ATCC 25853.

O sufixo Pedr foi utilizado para designar o local de coleta das amostras, seguido do número de coleta e as duas últimas letras representam o gênero e espécie bacteriana na qual os fagos foram obtidos e isolados.

Os ensaio para a determinação da amplitude de hospedeiros foi realizado de acordo com a metodologia descrita por Gregoracci (2006), utilizando as seguintes cepas bacterianas: Staphylococcus aureus ATCC 6338, Enterococcus faecalis ATCC 15290, Klebisiela pneumoniae ATCC 4352, Escherichia coli ATCC 8789 e Pseudomonas aeruginosa ATCC 25853, e a fórmula abaixo para a determinação das titulações virais de cada ensaio:

$$
P F U=\frac{\text { Número de placas de lise }}{\text { volume da diluição }(\mathrm{mL}) \times \text { fator de diluição }} \times \frac{1000 \mu \mathrm{L}}{\mathrm{mL}}
$$

Sendo a titulação viral o produto da equação acima, que considera a média da quantidade de placas formadas por cada fago em cada um dos hospedeiros mencionados ( $n=3$ para cada hospedeiro), dividido pelo volume da diluição empregada multiplicado pelo seu fator de diluição (de $10^{-3}$ à $\left.10^{-5}\right)$; na qual o quociente obtido no primeiro termo é multiplicado pelo segundo termo, cuja finalidade é ajustar o resultado para ser expresso em Unidades Formadoras de Placa por $\mathrm{mL}$. Para cada triplicata também foi calculada média, mais desvio padrão.

\section{RESULTADOS E DISCUSSÃO}

Quatro bacteriófagos líticos foram isolados de amostras de esgoto, o isolado Pedr3CEc inicialmente enriquecimento e posteriormente isolamento com Escherichia coli ATCC 8789, o isolado Pedr3CKp proveniente de enriquecimento e isolamento com Klebisiela pneumoniae ATCC 4352, o isolado Pedr3CSa, enriquecido e isolado com Staphylococcus aureus ATCC 6338, e o isolado Pedr3CPa, que foi enriquecido e isolado com a bactéria Pseudomonas aeruginosa ATCC 25853, podendo as características morfológicas das placas formadas por cada fago serem observadas na figura 1 e suas descrições na tabela 1.

A morfologia de placa, além de poder informar o tipo de ciclo de replicação viral, através de suas características, nas quais fagos que formam placas com aspecto límpido indicam a utilização do ciclo lítico, enquanto placas de aspeto turvo sugerem lisogênia (CASEY et al., 2018), também serve como um dos primeiros critérios de distinção entre fagos (SHENDE et al., 2017), e pode fornecer informações quanto aos 
tamanhos das partículas virais, nas quais, fagos grandes tendem a formar placas pequenas, enquanto fagos pequenos tendem a formar placas grandes (SAAD et al., 2019).

Podendo a relação entre tamanho de placa e tamanho de partícula viral ser observada nos resultados de Šimoliūnas et al. (2013), isolou o fago vB_KleM_RaK2, que possui genoma de $346 \mathrm{kbp}$, capsídeo de $123 \mathrm{~nm}$ de diâmetro e cauda de $128 \times 21,5 \mathrm{~nm}$, que formou placas pequenas de $0,75 \pm 0,25 \mathrm{~mm}$ de diâmetro, e os resultados de Kumari et al. (2010) isolou Podovírus com capsídeo de 73-135 nm de diâmetro e cauda de 15,18-40 nm, que formaram placas de 7,8 $\mathrm{mm}$.

Os resultados obtidos revelam que os fagos isolados performam o ciclo lítico como estratégia de replicação, e que possivelmente apresentam partículas virais de tamanho consideravelmente grande, entretanto, por se tratar de um estudo preliminar, ensaios de microscopia eletrônica de transmissão não foram realizados para confirmar esta relação entre tamanho de placa e tamanho de partícula viral, e possibilitar a classificação taxonômica dos isolados conforme preconizado pelo ICTV (International Committee on
Taxonomy of Viruses), assim como confirmação do processo de isolamento (BENIAC et al., 2014; ELBREKI et al., 2014; CASEY et al., 2018).

A amplitude de hospedeiro é uma característica intrínseca de cada bacteriófagos, e representa um parâmetro de distinção e classificação para estes vírus, podendo a amplitude de hospedeiros ser do tipo monovalente, quando infectam apenas uma espécie bacteriana, ou polivalente, quando infectam duas ou mais espécies bacterianas (TAN et al., 2008). Apresentando os Pedr3CEc, Pedr3CSa e Pedr3CPa, uma amplitude de hospedeiro do tipo polivalente, enquanto o isolado Pedr3CKp apresentou amplitude de hospedeiro do tipo monovalente, podendo a amplitude de hospedeiros de cada isolado ser observada com suas devidas titulações para cada hospedeiro na tabela 2.

De acordo com Shende et al. (2017), fagos com amplitude de hospedeiro do tipo polivalente possuem potencial para substituir os antibióticos, e os fagosPedr3Sa, Pedr3Ec e Pedr3Pa apresentaram amplitude deste tipo, porém, deve ser considerado que a investigação de fagos com o intuito de

Tabela 1. Características morfológicas do ensaio de placa.

\begin{tabular}{|c|c|c|c|c|}
\hline \multirow{2}{*}{$\begin{array}{l}\text { Bacteriófago } \\
\text { Isolado }\end{array}$} & \multicolumn{3}{|c|}{ Morfologia de placa } & \multirow[t]{2}{*}{ Títulação final (UFP/mL) } \\
\hline & Diametro (mm) & Forma & Aparencia & \\
\hline Pedr3CSa & 1,00 & $\begin{array}{l}\text { Circular, } \\
\text { regular }\end{array}$ & $\begin{array}{l}\text { Límpida, sem a presença de } \\
\text { halo ou centro }\end{array}$ & $4,6 \times 10^{5}$ \\
\hline Pedr3CPa & 2,00 & $\begin{array}{l}\text { Circular, } \\
\text { Irregular }\end{array}$ & $\begin{array}{l}\text { Límpida, sem a presença de } \\
\text { halo ou centro }\end{array}$ & $\begin{array}{l}\text { Acima do limite de } \\
\text { quantificação }\end{array}$ \\
\hline Pedr3CEc & 1,00 & $\begin{array}{l}\text { Circular, } \\
\text { Irregular }\end{array}$ & $\begin{array}{l}\text { Límpida, sem a presença de } \\
\text { halo ou centro }\end{array}$ & $3,1 \times 10^{5}$ \\
\hline Pedr3CKp & 1,00 & $\begin{array}{l}\text { Circular, } \\
\text { regular }\end{array}$ & $\begin{array}{c}\text { Límpida, sem a presença de } \\
\text { halo ou centro }\end{array}$ & $3,1 \times 10^{5}$ \\
\hline
\end{tabular}

Fonte: Os autores (2019).

Tabela 2. Resultados dos ensaio de amplitude de hospedeiro para cada isolado expressos em função da média das Unidades Formadoras de Placas por $\mathrm{mL}$ de cada fago por hospedeiro, seguido do desvio padrão da contagem do número de unidades formadoras de placas.

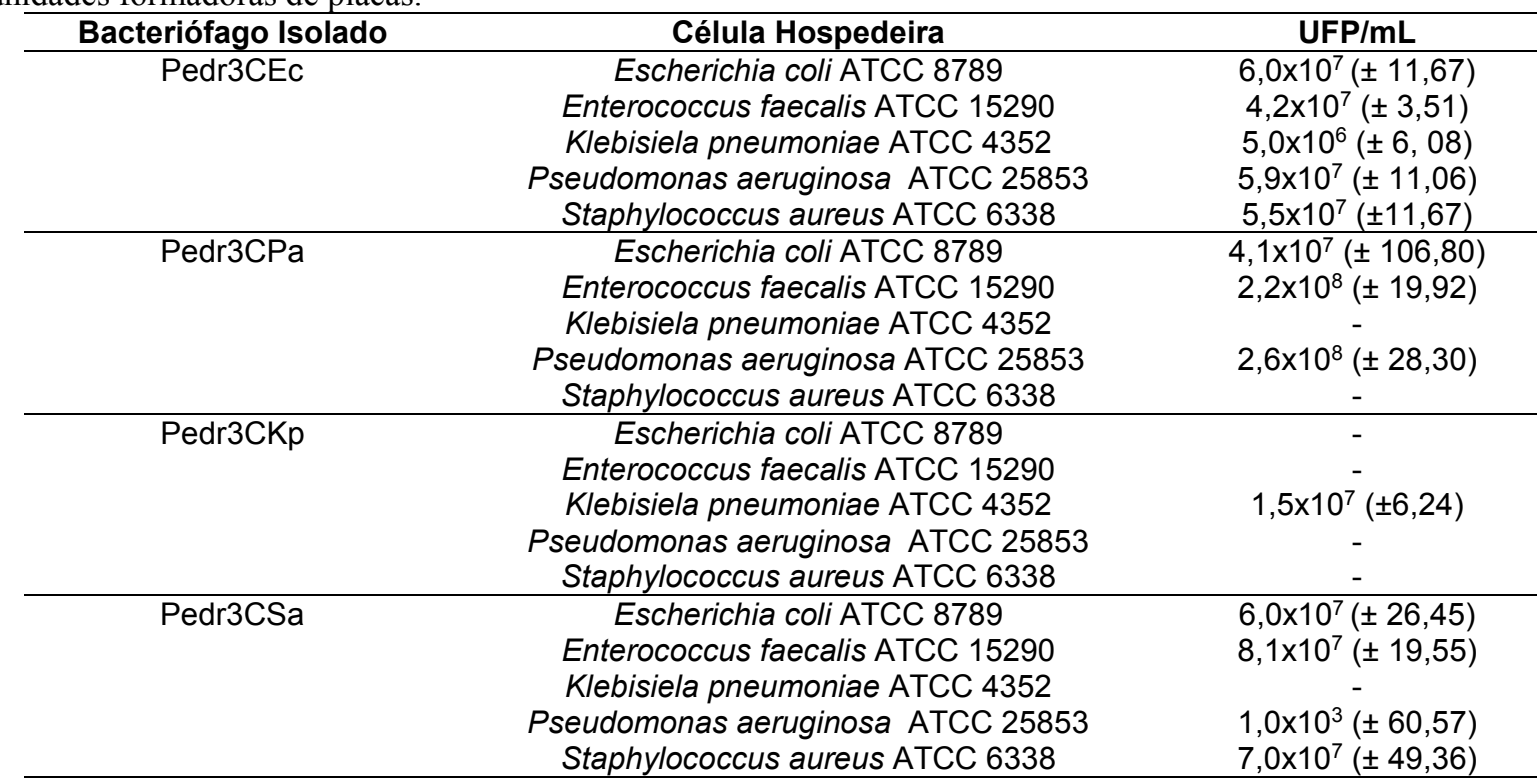

Fonte: Os autores (2019) 
aplicação na terapêutica contra infecções bacterianas é melhor conduzida com o emprego de isolados clínicos ao invés de isolados comerciais (ROSS et al., 2016), mas isso não inviabiliza o estudo realizando, uma vez que os resultados obtidos torna promissora a investigação da atividade lítica dos isolados frente a isolados clínicos circulantes na cidade ou em coleções de isolados resistentes existentes no País.

Figura 1. Placas de lise bacteriano promovidas pelos bacteriófagos líticos isolados com Pseudomonas aeruginosa acima a esquerda, com Klebisiela pneumoniae acima a direita, com Staphylococcus aureus abaixo a esquerda e com Escherichia coli abaixo a direita, podendo-se notar a uniformidade quanto a forma e tamanho das UFP.
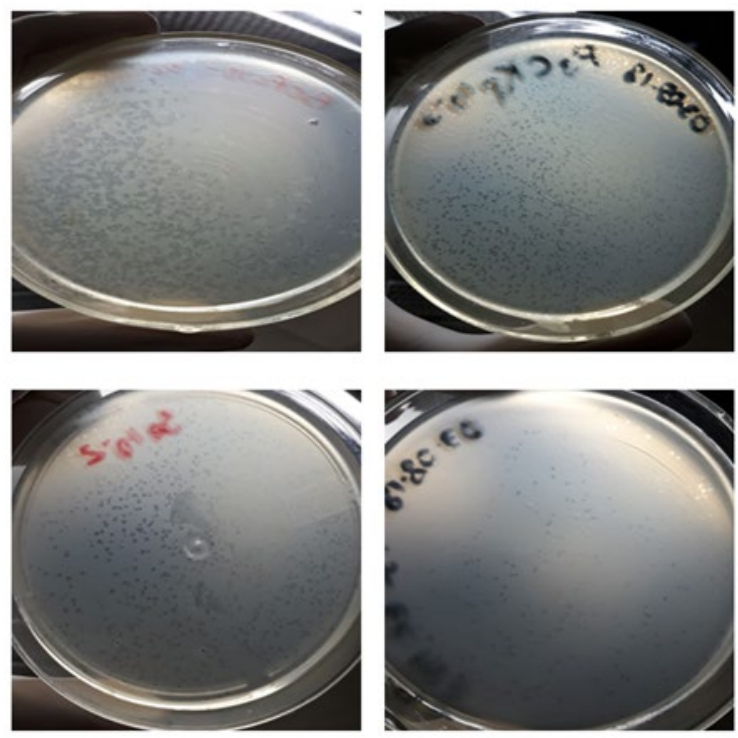

Em relação ao isolado Pedr3CKp, que apresentou amplitude de hospedeiro do tipo monovalente, Kingwell (2015) e Casey et al. (2018) afirmam que fagos monovalentes possuem potencial na terapia fágica, entretanto, é necessário um grande conhecimento sobre o patógeno a ser enfrentado para que os fagos sejam eficazes, podendo estes serem também empregados em coquetéis com outros fagos para ampliarem seu espectro de atividade em relação a sua utilização em monoterapia (apenas um fago).

Também sendo promissora a possibilidade de estudos de amplitude de hospedeiro com este isolado com outras cepas de Klebisiela pneumoniae para a avaliação de sua possível empregabilidade no diagnóstico desta espécie bacteriana por fago tipagem, como reportado por Sechter et al. (2000).

\section{CONCLUSÕES}

Os resultados demonstram que os fagos isolados possuem potencial empregabilidade em processos biotecnológicos para o controle de bactérias patogênicas, principalmente o isolado Pedr3CEc, porém, parcerias com diferentes instituições de pesquisa com infraestrutura apropriada devem ser estabelecidas para que mais estudos sejam realizados com o intuito de caracterizar os isolados conforme os critérios estabelecidos pelo ICTV, estender a caracterização da amplitude de hospedeiros com isolados clínicos das mesmas espécies testadas e espécies bacterianas distintas, e ensaios de estabilidade devem ser realizados para a que as condições fisiológicas ótimas destes organismos sejam conhecidas e futuramente aplicadas no desenvolvimento de formulações farmacêuticas para o tratamento de infecções bacterianas.

Sendo o isolado Pedr3Kp um achado peculiar, que talvez seja mais interessante ser estudado para o desenvolvimento de uma ferramenta diagnóstica para Klebisiela pneumoniae.

\section{AGRADECIMENTOS}

Ao Instituto de pesquisas científicas e tecnológicas do estado do Amapá e ao Laboratório de Toxicologia e Química Farmacêutica da Universidade Federal do Amapá

\section{REFERÊNCIAS}

ABEDON, STEPHEN T.; THOMAS-ABEDON, C. Phage Therapy Pharmacology. Current pharmaceutical biotechnology. v.11, p.28-47, 2010.

ABEADON, ST; KUHL, SJ; BLASDEL, BG; KUTTER, EM. Phage Treatment of Human Infections. Bacteriophage. v.1, n.2, p.66-84, 2011.

BENIAC, D. R. et al. A filtration based technique for simultaneous SEM and TEM sample preparation for the rapid detection of pathogens. Viruses, v. 6, n. 9, p. 33583371, 2014.

CASEY, E. et al., In vitro characteristics of phages to guide 'real life' phage therapy suitability. Viruses, v. 10, n. 4, p 1-20, 2018.

COHEN, M.L.; Changing patterns of infectious diseases. Nature, v. 406, p. 762-767, 2000.

COSTA, A. L. P.; SILVA-JÚNIOR, A. C. S. Resistência bacteriana aos antibióticos e Saúde Pública: uma breve revisão de literatura. Estação Científica (UNIFAP). v. 7, n. 2, p. 45-57, 2017.

ELBREKI, M. et al. Bacteriophages and Their Derivatives as Biotherapeutic Agents in Disease Prevention and Treatment. Journal of Viruses, v. 2014, p. 1-20, 2014.

FRUCIANO, E.; BOURNE, S. Phage as an antimicrobial agent: $\mathrm{d}^{\prime}$ Herelle's heretical theories and their role in the decline of phage prophylaxis in the West. Canadian Journal of 
Infectious Diseases and Medical Microbiology, v. 18, n. 1, p. 19-26, 2007.

GOLKAR, Z.; BAGASRA, O.; GENE PACE, D. Bacteriophage therapy: A potential solution for the antibiotic resistance crisis. Journal of Infection in Developing Countries, v. 8, n. 2, p. 129-136, 2014.

GREGORACCI, GB. Levantamento de bacteriófagos líticos: Isolamento e caracterização de vírus provenientes de esgoto comum com potencial aplicação antimicrobiana. 2006. 87f. Dissertação de Mestrado - Programa de pósGraduação em Genética e Biologia Molecular na área de Microbiologia, Universidade Estadual de Campinas, São Paulo.

HEYMANN, D.; DAR, O. Prevention is better than cure for emerging infectious diseases. British Medical Journal, v.348, p. 20-23, 2014.

KINGWELL, K. Bacteriophage Therapy re-enter clinical trials. Nature Reviews Drug Discovery.v.14, p. 515-516, 2015.

KUMARI, S.; HARJAI, K.; CHHIBBER, S. Isolation and characterization of Klebsiella pneumoniae specific bacteriophages from sewage samples. Folia Microbiologica, v. 55, n. 3, p. 221-227, 2010.

LOC-CARRILLO, C.; ABEDON, S. T. Pros and cons of phage therapy. Bacteriophage, v. 1, n. 2, p. 111-114, 2011.

MIRZAEI, MK; NILSSON, AS. Isolation of phages for phage therapy: a comparison of spot tests and efficiency of plating analysis for determination of host range and efficacy. Plos one. v.10, n.3, p.1-13, 2015

PELFRENE, E.; WILLEBRAND, E.; SANCHES, A.C.; SEBRIS, Z.; CAVALERI, M. Bacteriophage therapy: A regulatory perspective. Journal of Antimicrobial Chemotherapy, v. 71, n. 8, p. 2071-2074, 2016.

ROSS, A.; WARD, S.; HYMAN, P. More Is Better: Selecting for Broad Host Range Bacteriophages. Frontiers in Microbiology, v. 7, p. 1-6, 2016.

SAAD, A. M. et al. Systemic method to isolate large bacteriophages for use in biocontrol of a wide-range of pathogenic bacteria. Journal of Bioscience and Bioengineering, v. 127, n. 1, p. 73-78, 2019.

SECHTER, I.; MESTRE, F.; HANSEN, D. S. Twenty-three years of Klebsiella phage typing: a review of phage typing of 12 clusters of nosocomial infections, and a comparision of phage typing with $\mathrm{K}$ serotyping. Clinical Microbiology and Infection. v, 6, n. 5, p. 233-238, 2000.

SHENDE, R. K. et al. Isolation and characterization of bacteriophages with lytic activity against common bacterial pathogens. Veterinary World, v. 10, n. 8, p. 973978, 2017.

SIQUEIRA, C. M. M. Resistência aos Antibióticos: O uso inadequado dos antibióticos na prática clínica. Resista de la Organización de Farmacéuticos Iberoamericanos, v. 14, n. 1, p. 45-68, 2004.

ŠIMOLIŪNAS, E. et al. Klebsiella Phage vB_KleM-RaK2 - A Giant Singleton Virus of the Family Myoviridae. PLoS ONE, v. 8, n. 4, p. 1-11, 2013.

TAN, G. H.; NORDIN, M. S.; NAPSIAH, A. B. Isolation and characterization of lytic bacteriophages from sewage water. J. Trop. Agric., v. 36, n. 2, p.1-5, 2008.

VENTOLA, C. L. The Antibiotic resistance crisis part 1: Causes and threats. Pharmacy and therapeutics, v. 40, n. 4, p, 277$283,2015$.

Submissão: 23/08/2019

Aprovado para publicação: 09/10/2019 